\title{
Strategies for RUN1 Deployment Using RUN2 and REN2 to Manage Grapevine Powdery Mildew Informed by Studies of Race Specificity
}

\author{
Angela Feechan, Marianna Kocsis, Summaira Riaz, Wei Zhang, David M. Gadoury, M. Andrew Walker, \\ Ian B. Dry, Bruce Reisch, and Lance Cadle-Davidson
}

First and seventh authors: CSIRO Agriculture Flagship, Urrbrae, South Australia 5064, Australia; second author: Department of Plant Biology, University of Pécs, Pécs 7624, Hungary; third and sixth authors: Department of Viticulture and Enology, University of California, Davis 95616; fourth author: Institute of Plant and Environment Protection, Beijing Academy of Agriculture \& Forestry Sciences, Beijing 100097; fifth author: Plant Pathology and Plant-Microbe Biology Section, Cornell University, New York State Agricultural Experiment Station, Geneva 14456; eighth author: Horticulture Section, Cornell University, New York State Agricultural Experiment Station, Geneva; and ninth author: United States Department of Agriculture-Agricultural Research Service, Grape Genetics Research Unit, Geneva, NY 14456.

Present address of A. Feechan: School of Agriculture \& Food Science, University College Dublin, Belfield, Dublin 4, Ireland. Accepted for publication 4 March 2015.

\section{ABSTRACT}

Feechan, A., Kocsis, M., Riaz, S., Zhang, W., Gadoury, D. M., Walker, M. A., Dry, I. B., Reisch, B., and Cadle-Davidson, L. 2015. Strategies for RUN1 deployment using RUN2 and REN2 to manage grapevine powdery mildew informed by studies of race specificity. Phytopathology 105:1104-1113.

The Toll/interleukin-1 receptor nucleotide-binding site leucine-rich repeat gene, "resistance to Uncinula necator 1" (RUN1), from Vitis rotundifolia was recently identified and confirmed to confer resistance to the grapevine powdery mildew fungus Erysiphe necator (syn. U. necator) in transgenic $V$. vinifera cultivars. However, sporulating powdery mildew colonies and cleistothecia of the heterothallic pathogen have been found on introgression lines containing the RUN1 locus growing in New York (NY). Two E. necator isolates collected from RUN1 vines were designated NY1-131 and NY1-137 and were used in this study to inform a strategy for durable RUN1 deployment. In order to achieve this, fitness parameters of NY1-131 and NY1-137 were quantified relative to powdery mildew isolates collected from $V$. rotundifolia and $V$. vinifera on vines containing alleles of the powdery mildew resistance genes $R U N 1, R U N 2$, or REN2. The results clearly demonstrate the race specificity of $R U N 1, R U N 2$, and $R E N 2$ resistance alleles, all of which exhibit programmed cell death (PCD)-mediated resistance. The NY1 isolates investigated were found to have an intermediate virulence on RUN1 vines, although this may be allele specific, while the Musc4 isolate collected from $V$. rotundifolia was virulent on all RUN1 vines. Another powdery mildew resistance locus, $R U N 2$, was previously mapped in different $V$. rotundifolia genotypes, and two alleles (RUN2.1 and RUN2.2) were identified. The RUN2.1 allele was found to provide PCD-mediated resistance to both an NY1 isolate and Musc4. Importantly, REN2 vines were resistant to the NY1 isolates and RUN1REN2 vines combining both genes displayed additional resistance. Based on these results, RUN1-mediated resistance in grapevine may be enhanced by pyramiding with RUN2.1 or REN2; however, naturally occurring isolates in North America display some virulence on vines with these resistance genes. The characterization of additional resistance sources is needed to identify resistance gene combinations that will further enhance durability. For the resistance gene combinations currently available, we recommend using complementary management strategies, including fungicide application, to reduce populations of virulent isolates.
The wild North American grapevine species Vitis rotundifolia was recognized as early as 1889 as a source of resistance to powdery mildew (25). In 1919, a partially fertile hybrid was created between $V$. rotundifolia $(2 n=40)$ and $V$. vinifera $(2 n=38)(10)$. Subsequent backcrosses (BCs) revealed that powdery mildew resistance was inherited as a single dominant locus, "resistance to Uncinula necator 1" (RUN1), mapping to a region on chromosome (Chr) 12 $(1,27)$. Recently, a Toll/interleukin-1 receptor (TIR) nucleotidebinding site leucine-rich repeat $(N B-L R R)$ gene from the RUN1 locus was confirmed to confer resistance to Erysiphe necator (syn. $U$. necator) in transgenic $V$. vinifera wine grape cultivars (15). The $R U N 1$ gene is typical of most plant resistance $(R)$ genes which encode proteins with LRR domains, a central NB, and a variable $\mathrm{N}$

Corresponding author: L. Cadle-Davidson;

E-mail address: Lance.CadleDavidson@ars.usda.gov

A. Feechan and M. Kocsis are co-equal first authors.

*The $\boldsymbol{e}$-Xtra logo stands for "electronic extra" and indicates that one supplementary table is published online.

http://dx.doi.org/10.1094/PHYTO-09-14-0244-R

This article is in the public domain and not copyrightable. It may be freely reprinted with customary crediting of the source. The American Phytopathological Society, 2015. terminus comprising either a TIR domain or coiled-coil domain (8). The resistance mediated by RUN1 is associated with rapid programmed cell death (PCD), which prevents E. necator hyphal growth and sporulation (15).

Eastern North America is the likely center of origin for $E$. necator, because isolate populations collected from this region are much more genetically diverse than those found in Europe and Australia, where only genetic groups A and B have been found $(2,17)$. Although RUN1 appears to confer resistance to isolates in North America, Europe, and Australia, it can be overcome by an isolate (group M) from the southeastern region of North America, to which $V$. rotundifolia is native (15). Recently, powdery mildew cleistothecia were found on RUN1 introgression lines growing in a permanent research vineyard in New York State from 2008 to 2010 (6). This suggests that naive powdery mildew populations in New York may have evolved to overcome RUNI or, alternatively, that isolate variants were already present that could overcome $R U N 1$. This supports previous observations from other crops that individual $N B-L R R$ genes can be overcome in the field by rapidly evolving pathogen populations $(3,4,13)$. Resistance conferred by a single dominant $R$ gene is often short lived in the field. For example, resistance conferred by the powdery mildew $R$ gene $P l 2$, used in apple breeding programs, was found to have broken down in experimental orchards after only 6 years (7).

Therefore, complementary disease management strategies are needed to extend the durability of $N B-L R R$ genes. In breeding for 
durable grapevine powdery mildew resistance, the most common strategy has been to combine multiple $R$ genes in new cultivars in an attempt to improve resistance levels and durability (14). Pyramiding $R$ genes has been demonstrated to be effective in other crop plants. For example, combining $R$ genes against late blight in potato led to an additive resistance response (36). Combining four different $R$ genes in rice against rice blast, although not additive, was more efficient for maintaining resistance durability in the field (35). Several powdery mildew $R$ gene combinations have also been introduced into elite wheat cultivars using molecular markers (23).

The ability to combine multiple powdery mildew $R$ genes in grape breeding lines has only recently become possible due to the molecular mapping of several $R$ loci. For example, in $V$. rotundifolia, several allelic variants have been indicated by simple-sequence repeat (SSR) fingerprints at both the RUN1 locus on Chr 12 and $R U N 2$ locus on Chr 18 (33). In addition, the first mapped powdery mildew $R$ gene, $R E N 2$ from $V$. cinerea, maps to Chr 14 and confers partial resistance to grapevine powdery mildew $(9,32)$. However, unlike RUN1 (15), the mechanisms underlying the resistance mediated by RUN2 and REN2 are yet to be determined.

Understanding the mechanisms of resistance and their potential impacts on resistance durability requires knowledge of pathogen biology. Infection of the plant host by E. necator begins with conidial germination on the surface of green plant tissue, followed by the formation of a primary appressorium. A penetration hypha from the appressorium breaks through the cuticle and cell wall of the epidermal cell and is subtended by a globose feeding structure (haustorium), which envaginates the epidermal cell membrane (19). Successful formation of a functional haustorium is a requirement for further fungal development. The haustorium is surrounded by a plant cellderived extrahaustorial membrane (EHM). The fungus secretes effector proteins into the apoplast of the host (39) or across the EHM into the cytosol (38). The direct or indirect detection of these cytosolic effectors by NB-LRRs can trigger a rapid PCD resistance response. Thus, the strength and mechanism of resistance to powdery mildew, including resistance conferred by the $R$ genes described above, can be characterized from the quantification of fungal development and PCD induction at 48 to $72 \mathrm{~h}$ postinoculation (hpi) $(16,21,29,30)$.

The objective of the current study was to assess strategies for $R U N 1$ deployment and $R$ gene pyramiding in grapevine by studying the race specificity of the $R U N 1, R U N 2$, and REN2 alleles. The study of race specificity was enabled by a diverse collection of E. necator isolates obtained in a series of population genetic studies $(2,17)$ and following the discovery of naive isolates naturally infecting RUN1 vines in Geneva, NY (6).

\section{MATERIALS AND METHODS}

Grapevine germplasm development and genotyping. The grapevine germplasm described here was provided as in vitro plantlets by CSIRO or as green cuttings by the University of California-Davis or Cornell University. Potted vines were maintained in the United States Department of Agriculture-Agricultural Research Service (USDA-ARS) greenhouse in Geneva, NY to harvest optimum-quality leaves for uniform disease evaluations. V. vinifera 'Portan' and 'Tempranillo' expressing RUN1 (MrRGA10) were generated as described previously (15). Of the three Portan RUNI and three Tempranillo RUNI in vitro plantlets transferred from CSIRO to USDA-ARS, all three Portan vines but only one of the Tempranillo vines were successfully established and grown from in vitro plantlets. Details of parentage and resistance allele status of the other germplasm described here are provided in Tables 1 and 2 . $V$. rotundifolia 'Thomas' was a grandparent of NC6-15, a seedling from the original $V$. vinifera $\times V$. rotundifolia introgression of $R U N 1$

TABLE 1. Allelic profile of simple-sequence repeat (SSR) markers linked to the resistance loci RUNland RUN2 for cultivars and introgression lines used in this study ${ }^{\mathrm{a}}$

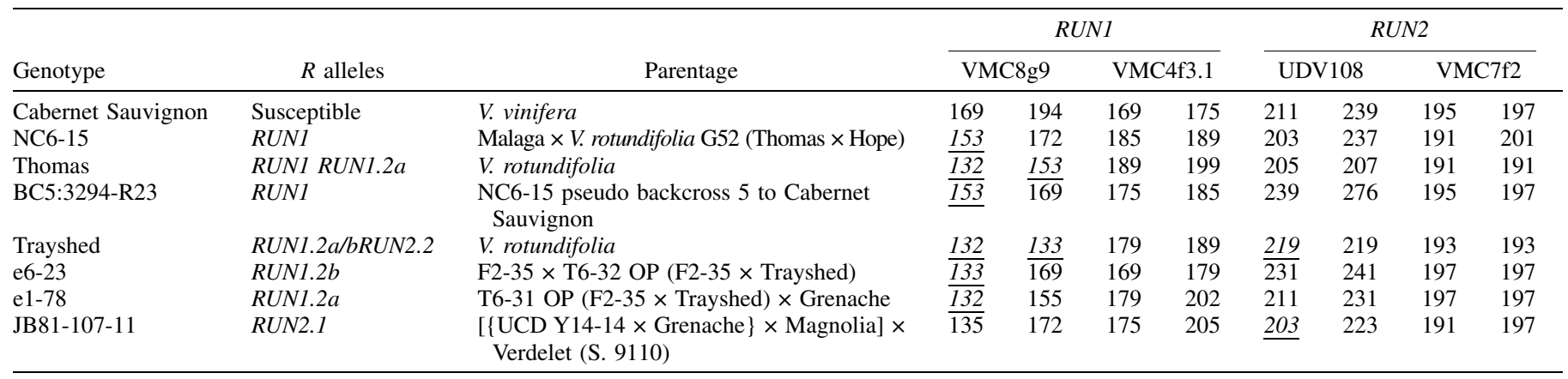

a SSR alleles that are linked to the resistance are underlined. The following resistance alleles were identified based on the SSR marker VMC8g9: RUN1 (153 bp), RUN1.2a (132 bp), and RUN1.2b (133 bp). The following resistance alleles were identified based on the SSR marker UDV108: RUN2.1 (203 bp) and RUN2.2 (219 bp).

TABLE 2. Resistance gene status of RUN1 and REN2 breeding lines used in this study ${ }^{a}$

\begin{tabular}{|c|c|c|c|c|c|}
\hline \multirow[b]{2}{*}{ Genotype } & \multirow[b]{2}{*}{ Parentage } & \multicolumn{2}{|c|}{ RUN1 } & \multicolumn{2}{|c|}{ REN2 } \\
\hline & & VMC8g9 159 bp & UDV-058 $154 \mathrm{bp}$ & VVIP26 144 bp & UDV-025 $124 \mathrm{bp}$ \\
\hline 119 (NY06.0506.02) & Arandell $\times$ Eger 99-11 (37-17-102) & + & + & + & + \\
\hline 123 (NY06.0506.01) & & + & + & + & + \\
\hline 4 (NY06.0514.04) & NY95.0308.01 × Eger 99-11 (37-17-108) & - & - & + & + \\
\hline 11 (NY06.0514.03) & & + & + & - & - \\
\hline 17 (NY06.0514.06) & $\ldots$ & + & + & + & + \\
\hline $61(\mathrm{NY} 06.0512 .02)$ & & + & + & - & - \\
\hline 100 (NY06.0509.02) & Eger 99-11 $(37-16-082) \times$ Arandell & + & + & + & + \\
\hline 113 (NY06.0509.01) & & + & + & + & + \\
\hline Chardonnay & $\ldots$ & - & - & - & - \\
\hline
\end{tabular}

a Symbols: + and - indicate presence and absence, respectively, of the resistance allele. 
carried out by Detjen in 1919 (10). NC6-15 was backcrossed to $V$. vinifera 'Cabernet Sauvignon', and BC5-3294-R23 is derived from five generations of this pseudo-backcrossing to different $V$. vinifera cultivars to avoid inbreeding depression, with the final cross also to Cabernet Sauvignon. 'Trayshed' is another powdery-mildewresistant $V$. rotundifolia cultivar and is homozygous for the RUN1.2 locus on $\mathrm{Chr} 12$ in addition to carrying another resistance locus, $R U N 2.2$, on Chr 18. Powdery-mildew-resistant breeding lines e1-78 and e6-23 lack RUN2.2 and represent both haplotypes (RUN1.2a and $R U N 1.2 b$ ) of Trayshed for Chr 12. The breeding line JB81-107-11 that was previously used to map the RUN2.1 locus on Chr 18 has a complex background (30), including $V$. rotundifolia 'Magnolia' as a grandparent. The REN2 locus from $V$. cinerea was inherited from the 'Arandell' (31) or NY95.0308.01 parent (Table 2). For studies involving REN2, the RUN1 locus was inherited from one of four Eger 99-11 full-sibling progeny (37-16-072, 37-16-082, 37-17-102, and $37-17-108)$ resulting from pollinating a RUN1 donor, 3082-1-42, with SK 90-2/19, an interspecific hybrid breeding line with $V$. amurensis, 'Traminer', 'Bianca', and 'Riesling' background.

To confirm the presence of the $R$ loci, DNA was extracted from young leaf material using the DNeasy 96 Plant Mini Kit (Qiagen, Valencia, CA) according to the manufacturer's directions or by modified cetyltrimethylammonium bromide procedure (33). Concentration and purity of DNA was determined by NanoDrop spectrophotometer (Wilmington, DE), and samples were normalized to $10 \mathrm{ng} / \mu \mathrm{l}$. The predictive allele sizes of the SSRs used in this study-VMC8g9 (1); UDV-025 and UDV-058 (11); VMC4f3.1, UDV108, VMC7f2 (33), and VVIP26 (GenBank BV140645.1) — are described in Tables 1 and 2. Fluorescently labeled forward primers were used to incorporate a fluorescence signal during the following thermocycling conditions: $30 \mathrm{~s}$ at $95^{\circ} \mathrm{C}$; followed by 35 cycles of $45 \mathrm{~s}$ at $95^{\circ} \mathrm{C}, 45 \mathrm{~s}$ at $58^{\circ} \mathrm{C}$, and $45 \mathrm{~s}$ at $72^{\circ} \mathrm{C}$; followed by $10 \mathrm{~min}$ at $72^{\circ} \mathrm{C}$. Detection by capillary electrophoresis for Table 2 was performed at the Core Laboratories Centre at Cornell University using an ABI 3730 DNA Analyzer (Life Technologies, Carlsbad, CA) with GeneScan-500 Liz Size Standard (Life Technologies). The SSR data were analyzed using Genographer 2.1.4 software. For Table 1, capillary electrophoresis detection was performed at the University of California-Davis using an ABI 3500
DNA Analyzer (Life Technologies) with GeneScan-500 Liz Size Standard (Life Technologies). The SSR data were analyzed using GeneMapper 4.1 software.

Collection and maintenance of $\boldsymbol{E}$. necator isolates. All E. necator isolates were maintained on surface-sterilized detached leaves of susceptible $V$. vinifera 'Chardonnay' on $1 \%$ water agar in petri dishes, as previously described (6). Isolate transfer was completed on a 10-day propagation cycle by dry tap transfer (i.e., gently tapping conidia from an infected leaf held above a new propagation leaf in an open petri dish). All inoculated leaves were incubated at $25^{\circ} \mathrm{C}$ under a cycle of $16 \mathrm{~h}$ of light and $8 \mathrm{~h}$ of darkness.

Isolates used in this study included two New York (NY) isolates collected from $V$. vinifera, LNYM ('Merlot'; Lockport, NY) and NY19 (Chardonnay; Burdett, NY) (2); two NY1 isolates collected from RUN1 full-sibling vines (with the parentage Eger 99-11 [37-17104] $\times$ Arandell) (6,31), NY1-137 (progeny 44-7-137) and NY1-131 (progeny 44-7-131); and one isolate collected from $V$. rotundifolia in Georgia, Musc4 $(2,15)$. Each isolate belongs to a different haplotype based on multilocus sequencing and SSR analysis $(2,17)$.

Powdery mildew disease assays. The fourth fully expanded leaf (glossy and translucent) was collected and used for all experiments described here. At the conclusion of the incubation period described for each experiment, leaves were cleared and stained with either trypan blue or Coomassie blue. For experiments visualized by trypan blue staining, whole leaves were inoculated with $E$. necator conidia by dry tap transfer of cultures at 10 days postinfection (dpi), as described above. At $48 \mathrm{hpi}$, infected leaves were stained in $10 \mathrm{ml}$ of trypan blue (lactic acid/phenol/ $\mathrm{dH}_{2} \mathrm{O} /$ glycerol $=1: 1: 1: 1$ by volume, and $2 \mathrm{mg}$ of trypan blue) in a $15-\mathrm{ml}$ Falcon tube at $90^{\circ} \mathrm{C}$ for $1 \mathrm{~h}$, as previously described (22). Leaves were cleared in chloral hydrate (2.5 $\mathrm{g} / \mathrm{ml}$ ) overnight and rinsed several times in water before mounting on a microscope slide in $50 \%$ glycerol. Trypan blue stains fungal structures and is a vital stain for cell death. At minimum, 100 germinated spores were scored on a leaf of each genotype using a compound light microscope. Infection structures were categorized as follows: (i) germinated spore with a haustorium and appressorium (Fig. 1C and D), (ii) germinated spore with a secondary hypha at least twice as long as the spore (Fig. 1A, B, and E), and (iii) the frequency of

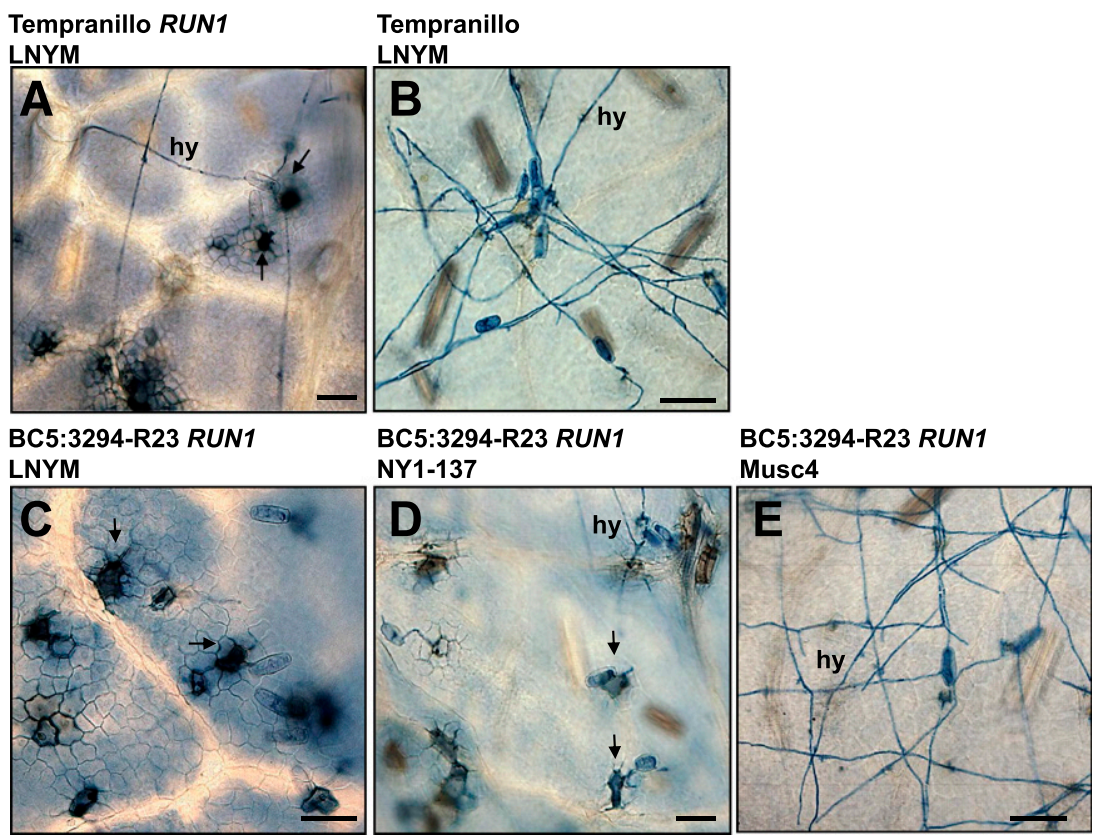

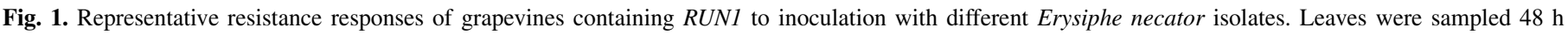

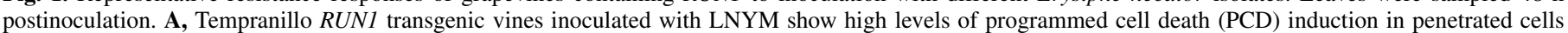

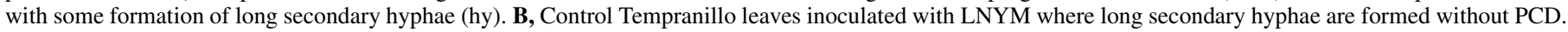

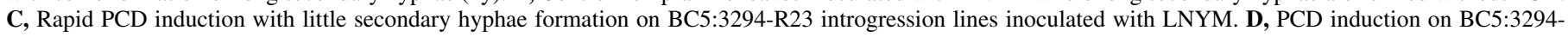

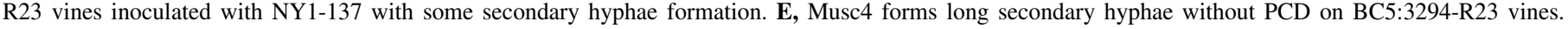
Trypan blue is a vital stain for dead cells. PCD is indicated by black arrows. Scale bar $=50 \mu \mathrm{M}$. 
PCD induction (see arrows in Fig. 1A, C, and D). The frequency of (ii) secondary hyphae formation or (iii) PCD was quantified relative to the proportion of spores that had successfully penetrated. One to two leaves were scored in two independent experiments for data presented in Figure 2. Two leaves were scored in three independent experiments for data presented in Figure 3. For comparisons between grapevine genotypes within isolate treatment and between isolate treatments within grapevine genotype, $P$ values were calculated using a Student's $t$ test and are presented in Supplementary Table S1.
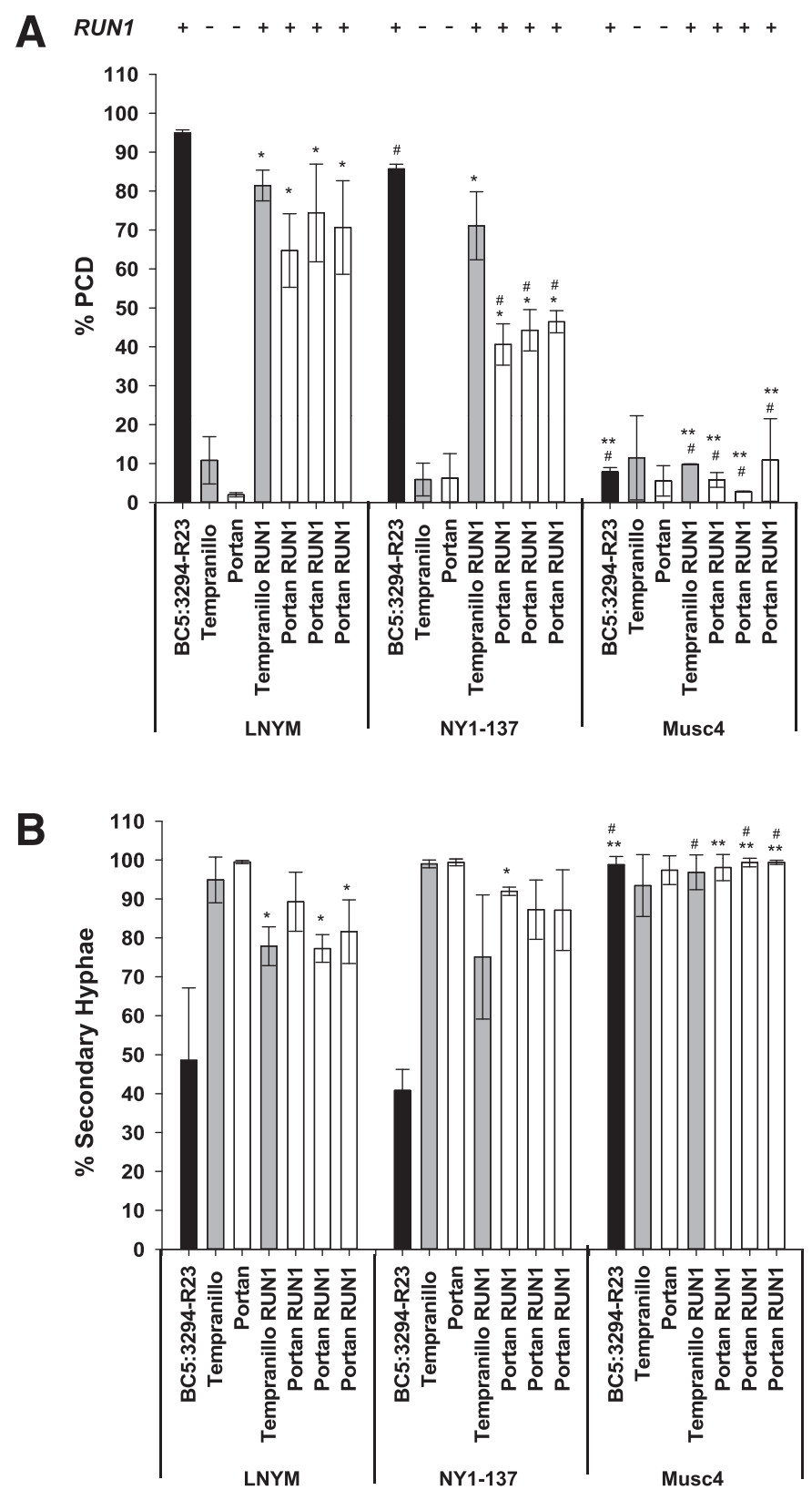

Fig. 2. Responses of grapevines containing RUN1 to inoculation with different Erysiphe necator isolates. Percentage of A, programmed cell death (PCD) or B, secondary hyphae formation on the introgression line BC5:3294-R23 (carrying the RUN1 locus) and Vitis vinifera Portan and Tempranillo lines with or without the RUN1 transgene following inoculation with the isolates LNYM, NY1-137, or Musc4. At least 100 germinated spores were scored $48 \mathrm{~h}$ postinoculation after trypan blue staining for cell death. Asterisks indicate a significant difference from the relevant control cultivars Portan or Tempranillo, hashes indicate a significant difference versus the same line challenged with LNYM, and double asterisks indicates a significant difference versus the same line challenged with NY1-137 $(\alpha<0.05$; Student's $t$ test). Each data point is the mean \pm standard deviation of two independent experiments where $(n=2)$.
For experiments visualized by Coomassie blue staining, inoculum spore suspensions were made by resuspending conidia (10 dpi) in $150 \mu \mathrm{l}$ of distilled water with $0.1 \%$ Tween-20 (Sigma-Aldrich, St. Louis), and adjusted to approximately $1 \times 10^{5}$ E. necator conidia $/ \mathrm{ml}$ based on hemacytometer counts. Leaf discs were drop-inoculated with a $10-\mu \mathrm{l}$ spore suspension. After $48 \mathrm{~h}$, leaf discs were cleared in 3:1 ( $\mathrm{vol} / \mathrm{vol}$ ) ethanol/acetic acid, changing the solution three to four times until the tissue was completely bleached, and then transferred to $50 \%$ ethanol for long-term storage. The solution was briefly replaced for 10 to $30 \mathrm{~s}$ with Coomassie stain (Coomassie Brilliant Blue R-250 [Sigma-Aldrich] at $0.12 \mathrm{~g} / \mathrm{liter}$ in $50 \%$ [vol $/ \mathrm{vol}$ ] methanol and $10 \%$ [vol/vol] glacial acetic acid) to stain the mycelium, then rinsed with several changes of water and mounted for viewing on a microscope slide in $50 \%$ glycerol. Infection structures were categorized as

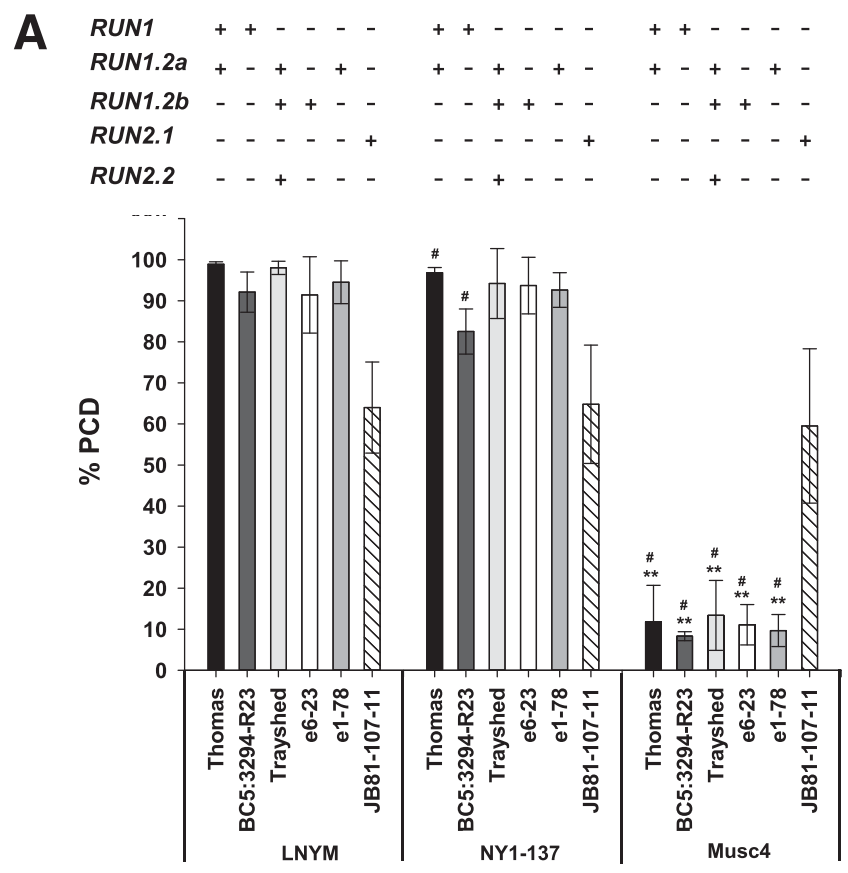

B

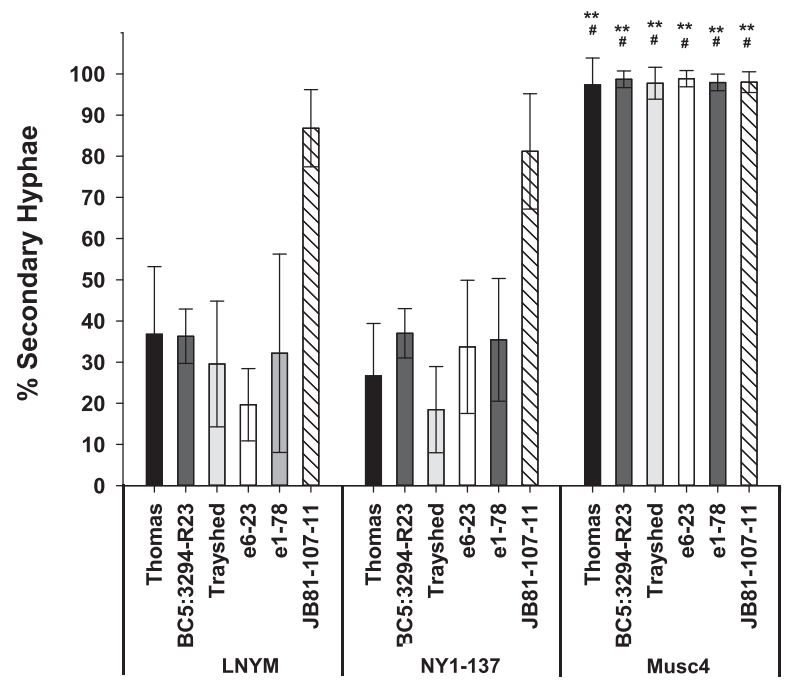

Fig. 3. Responses of grapevines containing RUN1 alleles or RUN2 to inoculation with different Erysiphe necator isolates. Percentage of A, programmed cell death (PCD) and $\mathbf{B}$, secondary hyphae formation on $V$. rotundifolia cultivars or breeding lines, $48 \mathrm{~h}$ postinoculation with the E. necator isolates LNYM, NY1-137, or Musc4. Hashes indicate a significant difference versus the same line challenged with LNYM and the double asterisks a significant difference versus the same line challenged with NY1-137 ( $\alpha<0.05$; Student's $t$ test). At least 100 germinated spores were scored. Each data point is the mean \pm standard deviation of three independent experiments $(n=2)$. 
follows: 100 spores per leaf disc were observed with a compound light microscope and categorized as (i) germinated spore with an appressorium (Fig. 4A), (ii) germinated spore with a secondary hypha at least twice as long as the spore (Fig. 4B), or (iii) germinated spore with multiple or branching secondary hypha (Figs. 4D and 5A and B). Colony success rate was quantified as the proportion of spores in category (iii) out of those that successfully penetrated; that is, (ii) and (iii). The colony success rate equation is an improvement over that of Ramming et al. (30), which calculated the proportion of (iii) out of all spores, resulting in an artifact of combining both penetration resistance and colony resistance. For data presented in Figures 4, 5, and 6 and Tables 3 and 4 , leaves were collected from two replicate shoots per vine and from two replicate vines per genotype. The experiment was conducted twice.

For measuring colonization and sporulation, whole leaves were drop-inoculated with $1 \times 10^{5}$ conidia/ml in four $10-\mu 1$ interveinal locations per leaf. Mycelium growth and sporulation were scored under $\times 15$ magnification at $10 \mathrm{dpi}$ and rated according to Miclot et al. (2012) (24) for mycelia, where $9=$ absent, $7=$ scattered, low density, 5 = widespread, low density, 3 = widespread, locally dense, and $1=$ widespread, dense; and for sporulation, where $9=$ absent, 7 = scattered, low density of conidia, $5=$ scattered, high density of conidia, 3 = widespread, moderate density of conidia, and $1=$ widespread, high density of conidia. Images were taken using QImaging camera with QCapture 3.1.2 software. Four replicate leaves were used per isolate-vine combination, and experiments were repeated three times.

\section{RESULTS}

$R U N 1$ resistance specificity to diverse isolates. Given that the NY1-137 isolate was observed growing on introgression lines containing the RUN1 locus in a vineyard in New York (6), we decided to further assess the race specificity of the RUN1 transgenic vines. Following inoculation with the E. necator isolates LNYM, Musc4, and NY1-137, PCD and the growth of secondary hyphae was scored as a measure of resistance in RUN1 transgenics, BC5: 3294-R23 vines (a RUN1 introgression line) (1), and the untransformed $V$. vinifera Portan and Tempranillo.

A high frequency of PCD was observed in epidermal cells associated with the penetration of LNYM isolates on both BC5:3294-R23 vines (94\%) (Figs. 1C and 2A) and transgenic RUNl vines (Figs. 1A and 2A) (64 to $81 \%$ ), compared with the untransformed Portan $(1 \%)$ and Tempranillo (10\%) (Figs. 1B and 2A). The high frequency of PCD in penetrated epidermal cells slightly reduced secondary hyphae formation at $48 \mathrm{hpi}$ in the RUN1 transgenics (77 to 89\%) compared with the untransformed cultivars (95 to 99\%) (Figs. 1A and B and 2B). The lowest rates of secondary hyphal growth were on BC5:3294-R23 vines (Figs. 1C and 2B).

Following challenge with the NY1-137 isolate, BC5:3294-R23 (86\%) and RUN1 transgenic lines of Tempranillo (71\%) and Portan (40 to 46\%) were also found to have significantly higher frequencies of PCD in penetrated epidermal cells than the untransformed controls (Figs. 1D and 2A). Although Portan RUN1 vines still had a significantly increased frequency of PCD compared with the untransformed vines, rates of PCD were significantly lower (24 to $30 \%$ ) than the same vines infected with the LNYM isolate (Fig. 2A). This suggests that RUN1 resistance in the Portan transgenic vines is partially compromised by the NY1-137 isolate. Interestingly, the frequency of PCD induction in Portan RUN1 vines in response to NY1-137 penetration was significantly lower than that observed in Tempranillo RUN1. PCD induction was also significantly reduced, albeit to a very low level, in BC5:3294-R23 inoculated with NY1-137 compared with LNYM (Fig. 2A). The formation of secondary hyphae was similar in all of the lines inoculated with NY1-137 with the exception of BC5:3294-R23 progeny which had much lower rates of secondary hyphae formation (Figs. 1D and 2B). Consistent with our previous findings (15), no significant increase in PCD was found on BC5:3294-R23 vines nor on any of the RUN1 vines following infection with the Musc4 isolate, and all lines had high rates of secondary hyphae formation (Figs. 1E and 2B) indicating the ineffectiveness of RUN1mediated resistance against this particular isolate.

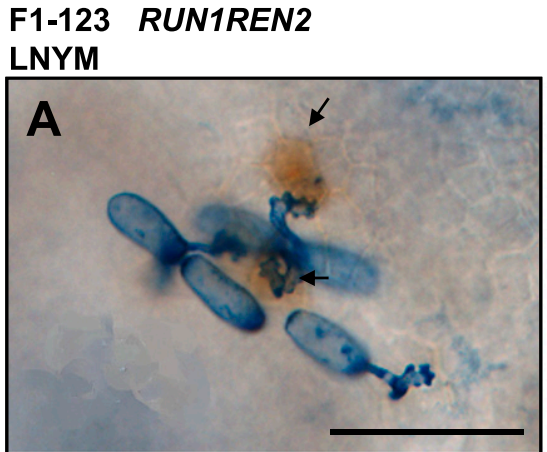

F1-119 RUN1REN2 NY1-137

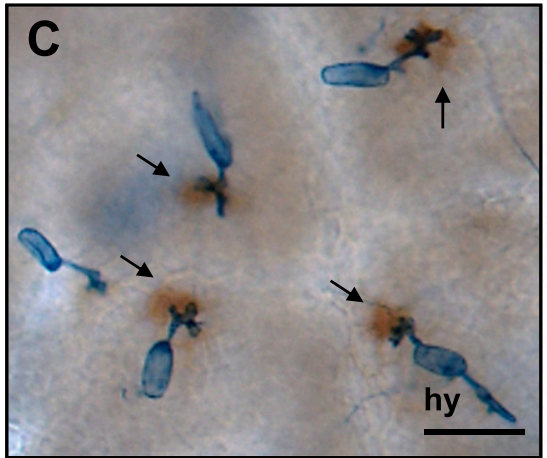

F1-123 RUN1REN2 NY1-131

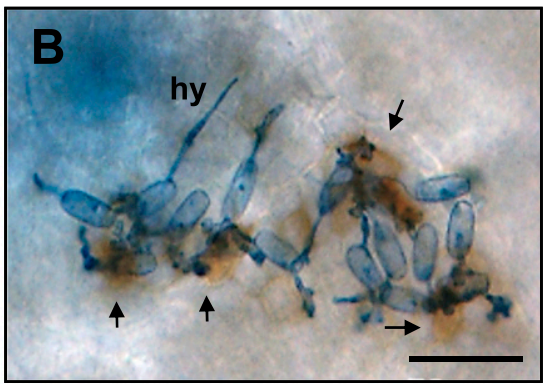

F1-123 RUN1REN2

Musc4

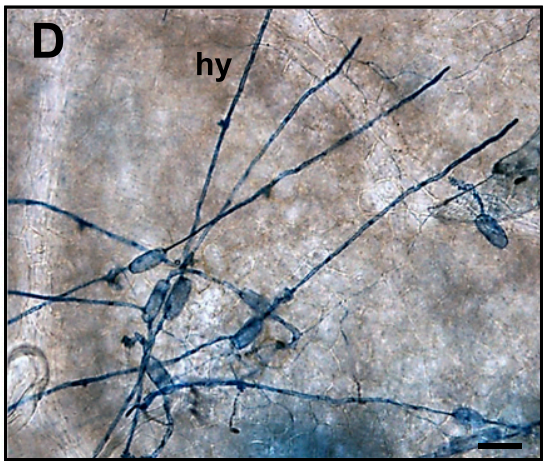

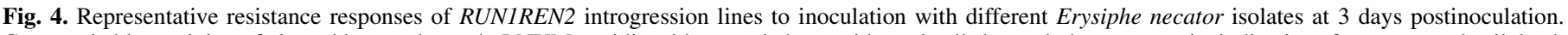

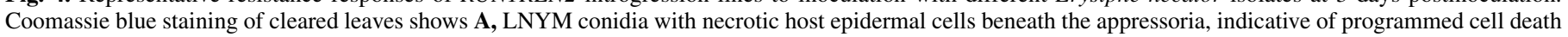

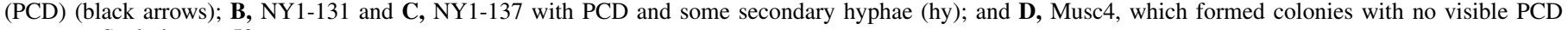
response. Scale bars $=50 \mu \mathrm{m}$. 
In order to test whether the differences in PCD observed between isolates would affect the fitness of the isolates, including colony formation and subsequent conidiation, we expanded the study to include more isolates and a longer incubation to allow conidiation. Colony density per field of view (the number of times a hypha crosses a vertical or horizontal transect) and conidiation were scored at 9 dpi. According to our data, NY1-131 and NY1-137 isolates are intermediate in virulence between LNYM and Musc4 on RUN1 vines, and fungal growth is sufficient for conidiation (Table 3). Surprisingly, an NY isolate from V. vinifera (NY19) had a similar capacity to colonize and conidiate on RUN1 vines, despite being collected from $V$. vinifera, suggesting that virulence on $R U N 1$ vines is not a rare trait in NY populations of E. necator (Table 3 ).

Race specificity of $R U N 1$ and $R U N 2$ alleles. In light of the existence of field isolates capable of breaking RUN1-mediated resistance and with a view to pyramiding grapevine powdery mildew $R$ genes, the race specificity of several different $R U N 1$ and RUN2 alleles from $V$. rotundifolia, as defined in Materials and Methods, was investigated in cultivars and breeding lines. Grapevine genotypes carrying various combinations of the RUN1 and RUN2 alleles (Table 1) were inoculated with powdery mildew isolates LNYM, NY1-137, and Musc4 and scored for percent PCD in penetrated epidermal cells. In response to LNYM infection, the RUN1.2a/b-containing genotypes, which include e1-78, e6-23, and Trayshed, as well as the RUN1-only genotype BC5:3294-R23 and the RUN1RUN1.2a genotype Thomas, all displayed similar levels of PCD (Fig. 3A) and secondary hyphae formation (Fig. 3B). However, the BC5:3294-R23 vine was found to have a small but significant reduction in PCD $(-10 \%)$ in response to NY1-137 compared with LNYM (Fig. 3A), which was also observed in the RUN1 source Thomas $(-3 \%)$ despite carrying both $R U N 1$ and $R U N 1.2 \mathrm{a}$ alleles. No significant differences were found in secondary hyphae formation for any of the RUN1- or RUN1.2a/b-containing vines when challenged with LNYM or NY1-137. Induction of PCD (8 to $13 \%$ ) was markedly reduced and secondary hyphae formation was high (97 to 99\%) for all RUN1 and RUN1.2a/b genotypes (Fig. 3) inoculated with Musc4.
In contrast, the RUN2.1 breeding line JB81-107-11 (33) was found to have an intermediate PCD response (60 to 65\%) to all three E. necator isolates investigated (Fig. 3A). Thus, although the RUN2.1-mediated resistance response in terms of $\mathrm{PCD}$ induction (Fig. 3A) appears to be lower than that induced by the RUN1, RUN1.2a, or RUN1.2b loci, it does not appear to be broken by the Musc 4 isolate. However, the frequency of secondary hyphal formation was found to be significantly lower on JB81-107-11 when challenged with LNYM (86\%) and NY1$137(81 \%)$ than Musc4 (98\%) (Fig. 3B). It should be noted that Trayshed, which combines $R U N 1.2 a / b$ and $R U N 2.2$ alleles, displayed PCD and secondary hyphal formation rates similar to other genotypes containing RUN1.2a or RUN1.2b only (Fig. 3). This suggests that, unlike RUN2.1, RUN2.2 is ineffective against the Musc4 isolate (Fig. 3).

$R E N 2$ - and $R U N 1$-mediated resistances are additive. The REN2 locus, which maps to $\mathrm{Chr} 14$, provides partial resistance to grapevine powdery mildew and is derived from $V$. cinerea $(9,32)$. Because REN2 originates from a completely different genetic background, it might be a useful candidate for pyramiding with RUN1. To test the ability of REN2 to complement RUN1 resistance, the powdery mildew isolates LNYM, NY19, NY1-131, NY1-137, and Musc 4 were tested for posthaustorial colony success rate on breeding lines with $R U N 1$ or REN2. The breeding lines were genotyped using four SSR markers to detect the presence of $R U N 1$ and $R E N 2 R$ genes (Table 2).

All isolates established colonies on Chardonnay with similarly high efficiency (88 to 92\%) (Figs. 5A and 6). In contrast, vines containing REN2 or RUN1 displayed marked resistance to E. necator colony formation (Figs. 5B and $\mathrm{C}$ and 6), and vines combining the two $R$ genes showed a trend of additive increased resistance to powdery mildew colony formation (Figs. 5A to D and 6). For example, LNYM established colonies at success rates of $30 \%$ on REN2 vines, $6 \%$ on RUN1 vines, and $2.6 \%$ on RUN1REN2 vines (Fig. 6). Rates of colony formation were also maintained at significantly lower rates on RUN1REN2 vines inoculated with isolates NY-19, NY1-131, and NY1-137 than vines with either REN2 or RUN1 R genes alone. Musc4

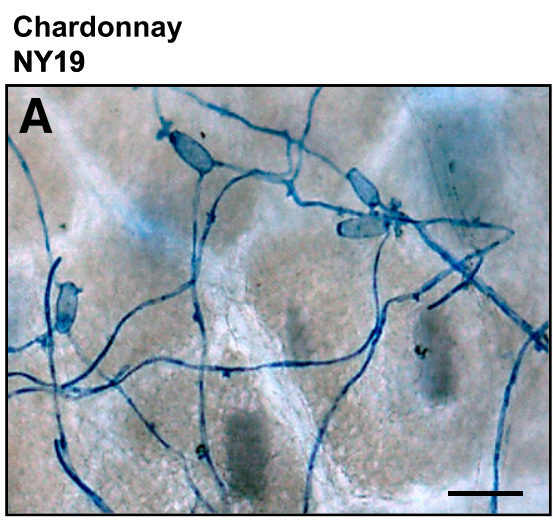

F1-4 REN2

NY19

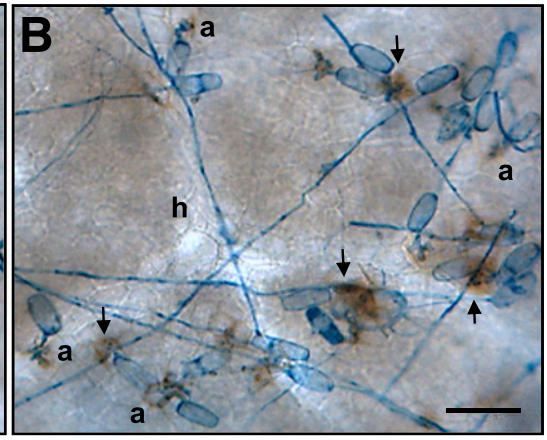

F1-123 RUN1REN2

NY19

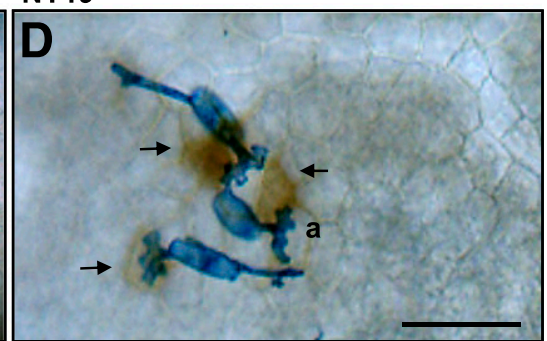

Fig. 5. Representative resistance responses of grapevines containing either the RUN1 or REN2 to inoculation with the Erysiphe necator NY19 isolate at $48 \mathrm{~h}$ postinoculation. Coomassie blue staining of cleared leaves shows A, frequent colony development with long secondary hyphae (hy) on Vitis vinifera Chardonnay, with no visible host response; B, colony development on REN2 with some conidia stopped at the appressorial (a) stage and some necrotic host epidermal cells indicative of programmed cell death (PCD) (black arrows); $\mathbf{C}$, some PCD and rare, long secondary hyphae on a RUN1 introgression indicating the ability of some conidia to form a colony; and $\mathbf{D}$, high frequency of PCD on a RUN1REN2 introgression line. Scale bar $=50 \mu \mathrm{M}$. 
established colonies on all vines (Figs. 4A and 6) with high efficiency, although colony formation was slightly lower than the Chardonnay controls (90\%) in REN2 (72\%), RUN1 (61\%), and RUN1REN2 (52\%) vines (Fig. 6).

To examine whether the minor but statistically significant reductions in colony success rate observed at 3 dpi between NY19, NY1-131, and NY1-137 would affect later fitness parameters, we quantified colony density and sporulation at 10 dpi compared with Musc4. All isolates grew well and sporulated extensively on detached leaves from Chardonnay. Independent of whether they contained RUNI or both RUN1 and REN2, leaves inoculated with NY19 formed scattered, lowdensity colonies (rating 7) but did not sporulate. However, colony development at 10 dpi was visibly reduced on leaves inoculated with either NY1-131 or NY1-137, when both RUN1 and REN2 (rating 7) were present, compared with leaves from vines that contained RUN1 alone (rating 5) (Table 4). Despite the widespread colony development of NY1-131, NY1-137, and Musc4 on RUN1 vines, only Musc4 was

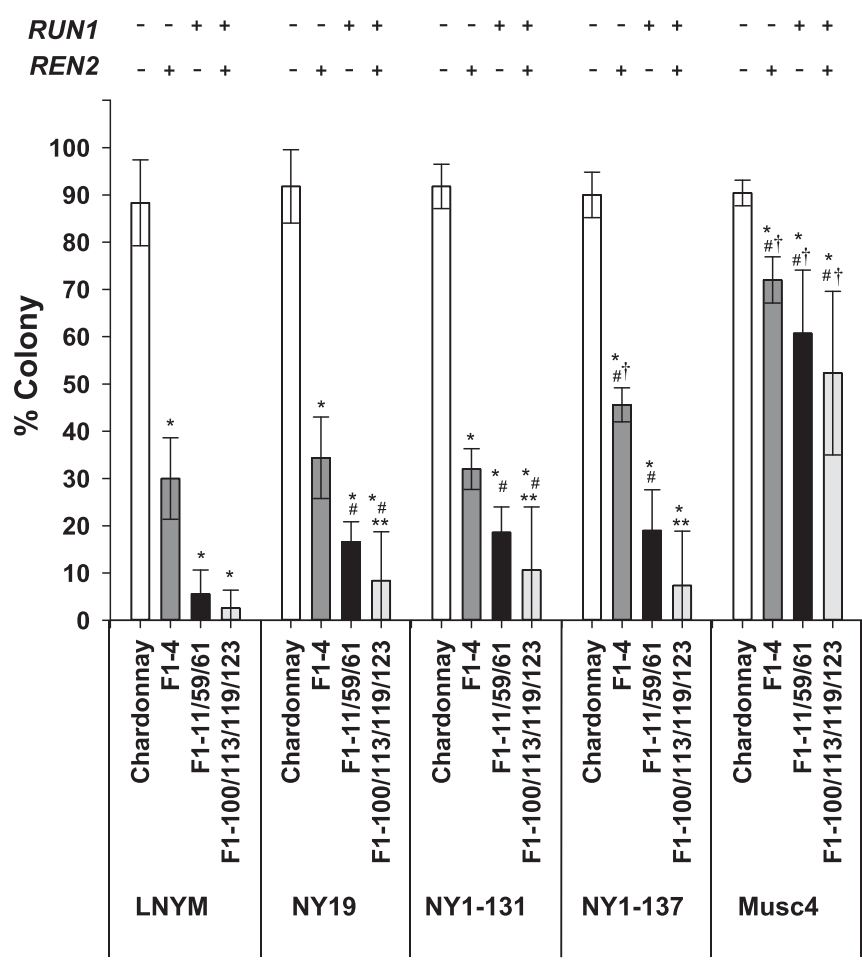

Fig. 6. Development of Erysiphe necator isolates on grapevine leaves containing RUN1 or REN2 relative to Vitis vinifera Chardonnay susceptible control. Colony success rate as indicated by the presence of multiple or branching secondary hyphae at $48 \mathrm{~h}$ postinoculation. At least 100 germinated spores were scored. Asterisks indicates a significant difference from Chardonnay controls, double asterisks indicates a significant difference from the vines containing RUN1 only and REN2 only (additive resistance), hashes indicate a significant difference from the same genotype with LNYM, and daggers indicate a significant difference from the same genotype with NY isolates $(\alpha<0.05$; Student's $t$ test). Each data point is the mean \pm standard deviation of three independent experiments $(n=4)$.

TABLE 3. Mean colony density per field of view (the number of times a hypha crosses a vertical or horizontal transect) and conidiation was scored 9 days postinfection $^{\mathrm{a}}$

\begin{tabular}{lccc}
\hline Isolate & Vitis vinifera Chardonnay & Portan RUN1 & BC5:3294-R23 \\
\hline LNYM & $\mathbf{7 3 . 9}( \pm \mathbf{1 0 . 0})$ & $1.0( \pm 0.8)$ & $1.6( \pm 1.3)$ \\
NY19 & $\mathbf{8 2 . 3}( \pm \mathbf{3 . 4})$ & $19.0( \pm 7.8)$ & $4.3( \pm 1.5)$ \\
NY1-131 & $\mathbf{8 1 . 1}( \pm \mathbf{0 . 8})$ & $19.9( \pm 15.4)$ & $1.4( \pm 2.0)$ \\
NY1-137 & $\mathbf{6 1 . 6}( \pm \mathbf{1 6 . 4})$ & $11.9( \pm 4.1)$ & $4.1( \pm 1.5)$ \\
Musc4 & $\mathbf{7 1 . 2}( \pm \mathbf{1 . 4})$ & $\mathbf{3 3 . 8}( \pm \mathbf{9 . 0})$ & $\mathbf{3 6 . 4}( \pm \mathbf{1 7 . 1})$ \\
\hline
\end{tabular}

a Chardonnay was included as a susceptible control and Erysiphe necator Musc4 was included as a positive control for pathogen compatibility. Bold indicates conidiation in two experiments $(n=3)$ and italics indicates conidiation in one experiment. Numbers in parentheses indicate \pm standard deviation. able to sporulate within 10 dpi. Similarly, only Musc4 sporulated on RUN1REN2 leaves within this 10-dpi experiment (Table 4).

\section{DISCUSSION}

During infection, pathogens secrete small effector molecules to suppress basal immune responses in plant cells and thereby facilitate penetration and colonization. Through evolution, certain plant species have evolved a second line of defense, referred to as effector-triggered immunity, whereby these pathogen effector molecules are recognized either directly or indirectly by R proteins that respond by triggering PCD (i.e., a hypersensitive response) $(8,13)$. However, $R$-gene-mediated defense is typically short lived due to the strong selection pressure that such resistance can exert upon pathogen populations, resulting in the rapid selection and subsequent increase of virulent isolates.

RUN1 was previously introduced into $V$. vinifera Portan and Tempranillo by genetic transformation and demonstrated to provide resistance to Australian and French powdery mildew isolates (15). Grapevines expressing RUN1 limit fungal development through PCD of the challenged epidermal cells and, therefore, fungal growth is arrested shortly after penetration; however, short secondary hyphal growth may occur between penetration and the onset of PCD (Fig. 1A). The ability of the fungus to form secondary hyphae may be indicative of a slower recognition or PCD response. If a pathogen subsequently evolves effectors that evade this recognition, a new pathogen race emerges, and resistance is overcome. Transgenic vines containing RUN1 displayed a strong PCD response to powdery mildew isolates collected from New York (LNYM and NY19) but not to isolate Musc4 collected from $V$. rotundifolia in Georgia $(2,15)$. However, the discovery of isolates NY1-131 and NY1-137, growing on RUN1 introgression lines in an experimental vineyard in New York (6), indicated that these RUN1virulent $E$. necator isolates may have arisen quickly (from planting of RUN1 vines in 2008 to collection of isolates from RUN1 vines in 2010). The current study confirms this original observation and demonstrates that these isolates are indeed more virulent on RUNI transgenics and introgression lines compared with the LNYM isolate (Figs. 2, 3, and 6). However, it is also clear that the virulence of these isolates on RUN1 genotypes is intermediate between the avirulent LNYM isolate and that of the virulent Musc4 isolate, which completely evades RUN1 recognition. Musc 4 originates from the same region of southeastern North America as V. rotundifolia, the source of RUN1. Whereas the coevolution of Musc4, along with $V$. rotundifolia, has led to the loss of Musc 4 recognition by RUN1, resulting in pathogenic specialization (18), it would appear that the NY1-131 and NY1-137 isolates are intermediate in their evolution to avoid RUN1 detection. Furthermore, NY19 and LNYM were collected from commercial vineyards and,

TABLE 4. Erysiphe necator isolate development 10 days postinfection on different grapevine genotypes with or without one, or two resistance genes

\begin{tabular}{llcc}
\hline Isolate & \multicolumn{1}{c}{ Genotype $R$ alleles } & Mycelia $^{\mathrm{a}}$ & Conidia $^{\mathrm{b}}$ \\
\hline NY19 & Chardonnay & 1 & 1 \\
& $F 1-11 / 59 / 61$ RUN1 & 7 & 9 \\
\multirow{3}{*}{ NY1-131 } & Ch-100/113/119/123 RUN1REN2 & 7 & 9 \\
& $F 1-11 / 59 / 61$ RUN1 & 1 & 1 \\
& $F 1-100 / 113 / 119 / 123$ RUN1REN2 & 5 & 9 \\
NY1-137 & Chardonnay & 7 & 9 \\
& $F 1-11 / 59 / 61$ RUN1 & 5 & 1 \\
Musc4 & $F 1-100 / 113 / 119 / 123$ RUN1REN2 & 7 & 9 \\
& Chardonnay & 1 & 9 \\
& $F 1-11 / 59 / 61$ RUN1 & 5 & 5 \\
& $F 1-100 / 113 / 119 / 123$ RUN1REN2 & 5 & 5 \\
\hline
\end{tabular}

a Mycelia or colony rating scale: $9=$ absent, $7=$ scattered, low density, $5=$ widespread, low density, 3 = widespread, locally dense, and $1=$ widespread, dense (Miclot et al. 2012).

b Conidia rating scale: $9=$ absent, $7=$ scattered, low density of conidia, $5=$ scattered, high density of conidia, 3 = widespread, moderate density of conidia, and 1 = widespread, high density of conidia (Miclot et al. 2012). 
therefore, represent a component of the natural variation of E. necator in commercial vineyards. The similarity of NY19 virulence to that of the NY1-131 and NY1-137 isolates suggests that the ability to colonize (Fig. 6; Table 3) and form cleistothecia (6) on RUN1 vines may be common among naïve New York isolates that have not previously encountered $R U N 1$, albeit to a much lower degree than isolates collected from $V$. rotundifolia. The ability to overcome $R U N 1$ may be indicative of different effector profiles present in the LNYM, NY1, and Musc4 isolates.

The current study also highlights the importance of the genetic background into which the $R$ genes are being introgressed or otherwise introduced. Previously, we identified two other putative $R$ genes at the $R U N 1$ locus, $R G A 4$ and $R G A 8$, which may also make minor additive contributions to powdery mildew resistance (15). BC5:3294-R23 contains the whole RUN1 locus introgressed; therefore, it is possible that the higher levels of resistance observed in this line, in comparison with the transgenic lines containing RUN1 only (Fig. 2), are due to the additive action of $R G A 4, R G A 8$, and $R U N 1$ at this locus. However, it is also interesting that RUN1 conferred higher frequencies of PCD against NY1-137 on Tempranillo than on Portan (Fig. 2), suggesting that genetic background may have a significant effect on the expression of resistance. This has been demonstrated in other pathosystems; for example, the bacterial blight (Xanthomonas oryzae pv. oryzae) $R$ gene $\mathrm{Xa3} / \mathrm{Xa} 26$ is differentially regulated by the genetic background of rice and functions better in the japonica background than in indica (40). Therefore, unknown alleles at other unknown loci may be contributing to powdery mildew resistance among the cultivars and breeding lines used in this study.

The SSR marker VMC8g9 is tightly linked to RUN1. BC5:3294R23 is derived from five generations of pseudo-backcrossing of NC615 to different $V$. vinifera cultivars to avoid in-breeding depression. NC6-15 has a VMC8g9 allele combination of 153/172. Thomas, which is a grandparent of NC6-15, shares the 153-bp allele with NC615 and BC5:3294-R23. The breeding lines e1-78 and e6-23 are both derived from Trayshed and each has one of Trayshed's RUN1.2a/b alleles (132/133) at this locus. Interestingly, Thomas also shares the RUN1.2a allele but this was not inherited by NC6-15. This suggests that there may be three different $R U N 1$ alleles, designated as $R U N 1$, $R U N 1.2 a$, and $R U N 1.2 b$. They appear to mediate similar PCD responses to the isolates tested, although the RUN1-containing vines Thomas and BC5:3294-R23 show a small but significant reduction in PCD level when challenged with NY1-137 compared with LNYM, which was not observed in vines with only the $R U N 1.2 a / b$ allele combinations (Fig. 3). This may suggest either the beginning of evolution to avoid detection by this specific RUN1 allele (153 bp) or it may reflect the genetic background of BC5:3294-R23, which is predominantly $V$. vinifera.

JB81-107-11 is a breeding line with a complex background, including the $V$. rotundifolia genotypes Trayshed and Magnolia. Field studies in California (where only the E. necator group B has been found) show that JB81-107-11 is resistant to powdery mildew. This resistance, designated $R U N 2.1$, segregates with the SSR marker UDV108 on Ch18, with a resistance allele (202 bp) shared with Magnolia at this locus (33). This previous study also identified resistance at this locus derived from Trayshed but with a different allelic profile, which was designated RUN2.2 (33). Our results show that, whereas Trayshed (RUN1.2a/b and RUN2.2) was completely susceptible to the Musc4 isolate, the intermediate resistance response of JB81-107-11 (RUN2.1) was maintained at a consistent level across all powdery mildew isolates tested, including Musc4 (Fig. 3). This suggests that RUN2.1 is able to recognize and mount a resistance response against the Musc4 isolate while RUN2.2 is not. Such differences in race specificity between RUN2.1 and $R U N 2.2$ would not have been detected in the previous studies by Riaz et al. (33) because of their use of group B isolates. Based on our assessment of the race specificity of the different powdery mildew $R$ genes sourced from
$V$. rotundifolia, it would appear that $R U N 2.1$ (or another $R$ gene from JB81-107-11) is a good candidate to pyramid with RUN1. However, other E. necator isolates are known to overcome JB81-107-11 resistance and produce conidia (30). Studies with root knot nematode (RKN) $R$ genes showed that pyramiding two different $R$ genes in one genotype suppressed the emergence of virulent $\mathrm{RKN}$ isolates. The authors concluded that pyramiding two distinct $R$ genes into a single cultivar could be a secure and durable strategy (12). This suggests that the combination of the two $R$ genes $R U N 1$ and $R U N 2.1$ may provide a strategy for improved durability of resistance to powdery mildew infection in the vineyard.

Another potential option for pyramiding with RUN1 is the REN2 powdery mildew resistance locus from $V$. cinerea $(9,32)$. REN2 significantly reduced infection by all powdery mildew isolates tested, including Musc4 (Fig. 6). Furthermore, our results clearly demonstrate that grapevine genotypes in which both RUN1 and REN2 are combined show greater resistance against powdery mildew isolates NY19, NY1-131, and NY1-137, in terms of both colony formation at $48 \mathrm{hpi}$ (Figs. 4A to $\mathrm{C}$ and 6) and mycelial growth at 10 dpi (Table 4), than is achieved by RUN1 alone. Although this additive resistance was also observed at $48 \mathrm{hpi}$ against Musc 4 , by 10 dpi there was no discernable difference between RUN1 and RUN1REN2 vines on the level of Musc4 growth or sporulation (Table 4). There is good evidence to indicate that the durability of major qualitative $R$ genes may be influenced by genetic background (26). For example, the $R$ gene $p v r 2$ (potato virus resistance) was defeated at high frequency when introgressed into a susceptible genetic background but it was not overcome when combined with a quantitative trait locus for partial resistance (26). Furthermore, combining Rlm6 (resistance to Leptosphaeria maculans) with quantitative resistance was found to increase the durability of this $R$ gene in Brassica napus (5). Therefore, it is likely that combining RUN1 qualitative resistance with REN2 quantitative resistance may also improve the durability of resistance to E. necator isolates.

For every isolate tested except Musc4, frequent host PCD was observed on RUN1, REN2, and RUN1REN2 vines at 2 and 3 dpi (Figs. 4 and 5). In spite of this PCD, the fungus was often able to form microscopically visible colonies by $48 \mathrm{hpi}$ and macroscopically visible colonies by $10 \mathrm{dpi}$ (Fig. 6; Table 4). This phenotype of PCD that appears to trail the leading edge of hyphal growth was first described for isolates that overcame RUN2.1 resistance from JB81107-11 and was referred to as trailing necrosis (30). As mentioned above, the effector profile of the different $E$. necator isolates may determine the speed of recognition and PCD induction by the host $R$ genes. That having been said, the trailing PCD observed here appears to be sufficient to reduce hyphal density and prolong the latent period, resulting in economically significant resistance.

The previous collection, genotyping, and analysis of grapevine powdery mildew isolates $(2,17)$, together with the characterization of these isolates by this and previous studies, can now begin to inform strategies for the deployment of powdery mildew $R$ genes in grapevine. However, such studies are still severely limited by welljustified restrictions on the distribution of different powdery mildew isolates to different countries or regions in which new resistant grapevine germplasm may be located. Recently, barley powdery mildew effector candidates were identified $(20,34)$. A subset of these have now been functionally characterized $(28,39)$ and confirmed as having virulence functions. We are now undertaking research to identify the powdery mildew effector candidates secreted by $E$. necator and to determine which of these are recognized by $R$ genes such as RUN1 and RUN2.1. The identification of these avirulence effectors will enable us to investigate the effector specificity of different powdery mildew $R$ genes, without requiring access to the powdery mildew isolates. This approach has been used successfully to inform potato breeders about the race specificity of genes conferring resistance to late blight Phytophthora infestans and assist in devising scientifically sound strategies for pyramiding $R$ genes to increase durability in the field (37). 


\section{ACKNOWLEDGMENTS}

This work was supported by research travel fellowships for A. Feechan and M. Kocsis to complete this work in Geneva, NY: an NSF-Grape Research Coordination Network (DBI 0741876) Stipend and a Miklós Faust Scholarship, respectively. We thank P. Kozma of the University of Pécs, Hungary, for supplying seed of population Eger 99-11 to B. Reisch. Mention of trade names or commercial products is solely for the purpose of providing specific information and does not imply recommendation or endorsement by the U.S. Department of Agriculture. USDA is an equal opportunity provider and employer.

\section{LITERATURE CITED}

1. Barker, C. L., Donald, T., Pauquet, J., Ratnaparkhe, M. B., Bouquet, A., Adam-Blondon, A. F., Thomas, M. R., and Dry, I. 2005. Genetic and physical mapping of the grapevine powdery mildew resistance gene, Runl, using a bacterial artificial chromosome library. Theor. Appl. Genet. 111:370-377

2. Brewer, M. T., and Milgroom, M. G. 2010. Phylogeography and population structure of the grape powdery mildew fungus, Erysiphe necator, from diverse Vitis species. BMC Evol. Biol. 10:268.

3. Bronson, C. R., and Ellingboe, A. H. 1986. The influence of four unnecessary genes for virulence on the fitness of Erysiphe graminis f. sp. tritici. Phytopathology 76:154-158.

4. Brown, J. K. M. 2003. Little else but parasites. Science 299:1680-1681.

5. Brun, H., Chèvre, A. M., Fitt, B. D., Powers, S., Besnard, A. L., Ermel, M., Huteau, V., Eber, F., Renard, M., and Andrivon, D. 2010. Quantitative resistance increases the durability of qualitative resistance to Leptosphaeria maculans in Brassica napus. New Phytol. 185:285-299.

6. Cadle-Davidson, L., Mahanil, S., Gadoury, D. M., Kozma, P., and Reisch, B. I. 2011. Natural infection of Run1-positive vines by naïve genotypes of Erysiphe necator. Vitis 50:173-175.

7. Caffier, V., and Laurens, F. 2005. Breakdown of $P l 2$, a major gene of resistance to apple powdery mildew, in a French experimental orchard. Plant Pathol. 54:116-124.

8. Collier, S. M., and Moffett, P. 2009. NB-LRRs work a "bait and switch" on pathogens. Trends Plant Sci. 14:521-529.

9. Dalbò, M. A., Ye, G. N., Weeden, N. F., Wilcox, W. F., and Reisch, B. I. 2001. Marker-assisted selection for powdery mildew resistance in grapes. J. Am. Soc. Hortic. Sci. 126:83-89.

10. Detjen, L. R. 1919. The limits in hybridisation of Vitis rotundifolia with related species and genera. N. C. Agric. Exp. Stn. Bull. 17: 409-442.

11. Di Gaspero, G., Cipriani, G., Marrazzo, M. T., Andreetta, D., Castro, M. J. P., Peterlunger, E., and Testolin, R. 2005. Isolation of (AC) nmicrosatellites in Vitis vinifera $\mathrm{L}$. and analysis of genetic background in grapevines under marker assisted selection. Mol. Breed. 15:11-20.

12. Djian-Caporalino, C., Palloix, A., Fazari, A., Marteu, N., Barbary, A., Abad, P., Sage-Palloix, A. M., Mateille, T., Risso, S., Lanza, R., Taussig, C., and Castagnone-Sereno, P. 2014. Pyramiding, alternating or mixing: Comparative performances of deployment strategies of nematode resistance genes to promote plant resistance efficiency and durability. BMC Plant Biol. 14:53.

13. Dou, D. L., and Zhou, J. M. 2012. Phytopathogen effectors subverting host immunity: Different foes, similar battleground. Cell Host Microbe 12: 484-495.

14. Eibach, R., Zyprian, E., Welter, L., and Topfer, R. 2007. The use of molecular markers for pyramiding resistance genes in grapevine breeding. Vitis 46:120-124.

15. Feechan, A., Anderson, C., Torregrosa, L., Jermakow, A., Mestre, P., Wiedemann-Merdinoglu, S., Merdinoglu, D., Walker, A. R., Cadle-Davidson, L., Reisch, B., Aubourg, S., Bentahar, N., Shrestha, B., Bouquet, A., Adam-Blondon, A.-F., Thomas, M. R., and Dry, I. B. 2013. Genetic dissection of a TIR-NB-LRR locus from the wild North American grapevine species Muscadinia rotundifolia identifies paralogous genes conferring resistance to major fungal and oomycete pathogens in cultivated grapevine. Plant J. 76: 661-674.

16. Feechan, A., Kabbara, S., and Dry, I. B. 2011. Mechanisms of powdery mildew resistance in the Vitaceae family. Mol. Plant Pathol. 12: 263-274.

17. Frenkel, O., Portillo, I., Brewer, M. T., Péros, J. P., Cadle-Davidson, L., and Milgroom, M. G. 2012. Development of microsatellite markers from the transcriptome of Erysiphe necator for analysing population structure in North America and Europe. Plant Pathol. 61:106-119.

18. Gadoury, D. M., and Pearson, R. C. 1991. Heterothallism and pathogenic specialization in Uncinula necator. Phytopathology 81: 1287-1293.
19. Gadoury, D. M., Wakefield, L. M., Cadle-Davidson, L., Dry, I. B., and Seem, R. C. 2012. Effects of prior vegetative growth, inoculum density, light, and mating on conidiation of Erysiphe necator. Phytopathology 102: 65-72.

20. Godfrey, D., Böhlenius, H., Pedersen, C., Zhang, Z., Emmersen, J., and Thordal-Christensen, H. 2010. Powdery mildew fungal effector candidates share N-terminal Y/F/WxC-motif. BMC Genom. 11:317.

21. Hoffmann, S., Di Gaspero, G., Kovács, L., Howard, S., Kiss, E., Galbács, Z., Testolin, R., and Kozma, P. 2008. Resistance to Erysiphe necator in the grapevine 'Kishmish vatkana' is controlled by a single locus through restriction of hyphal growth. Theor. Appl. Genet. 116:427-438.

22. Koch, E., and Slusarenko, A. 1990. Arabidopsis is susceptible to infection by a downy mildew fungus. Plant Cell 2:437-445.

23. Liu, J., Liu, D., Tao, W., Li, W., Wang, S., Chen, P., Cheng, S., and Gao, D. 2000. Molecular marker-facilitated pyramiding of different genes for powdery mildew resistance in wheat. Plant Breed. 119:21-24.

24. Miclot, A.-S., Wiedemann-Merdinoglu, S., Duchéne, E., Merdinoglu, D., and Mestre, P. 2012. A standardised method for the quantitative analysis of resistance to grapevine powdery mildew. Eur. J. Plant Pathol. 133: 483-495.

25. Olmo, H. P. 1986. The Potential Role of (Vinifera $\times$ Rotundifolia) Hybrids in Grape Variety Improvement. Experientia 42:921-926.

26. Palloix, A., Ayme, V., and Moury, B. 2009. Durability of plant major resistance genes to pathogens depends on the genetic background, experimental evidence and consequences for breeding strategies. New Phytol. 183:190-199.

27. Pauquet, J., Bouquet, A., This, P., and Adam-Blondon, A. F. 2001. Establishment of a local map of AFLP markers around the powdery mildew resistance gene Runl in grapevine and assessment of their usefulness for marker assisted selection. Theor. Appl. Genet. 103:1201-1210.

28. Pliego, C., Nowara, D., Bonciani, G., Gheorghe, D. M., Xu, R., Surana, P., Wigham, E., Nettleton, D., Bogdanove, A. J., Wise, R. P., Schweizer, P., Bindschedler, L. V., and Spanu, P. D. 2013. Host-induced gene silencing in barley powdery mildew reveals a class of ribonuclease-like effectors. Mol. Plant-Microbe Interact. 26:633-642.

29. Ramming, D. W., Gabler, F., Smilanick, J., Cadle-Davidson, M., Barba, P., Mahanil, S., and Cadle-Davidson, L. 2011. A single dominant locus, Ren4, confers rapid non-race-specific resistance to grapevine powdery mildew. Phytopathology 101:502-508.

30. Ramming, D. W., Gabler, F., Smilanick, J. L., Margosan, D. A., Cadle-Davidson, M., Barba, P., Mahanil, S., Frenkel, O., Milgroom, M. G., and Cadle-Davidson, L. 2012. Identification of race-specific resistance in North American Vitis spp. limiting Erysiphe necator hyphal growth. Phytopathology 102:83-93.

31. Reisch, B. I., Luce, R. S., and Mansfield, A. K. 2014. 'Arandell'-A disease-resistant red wine grape. HortScience 49:503-505.

32. Reisch, B. I., Mahanil, S., Consolie, N., Luce, R. S., Wallace, P. G., and Cadle-Davidson, L. 2014. Examination of marker-assisted selection for powdery and downy mildew resistance. In: Proc. 10th Int. Conf. Grapevine Breed. Genet. Geneva, NY. B. I. Reisch and J. Londo, eds. Acta Hortic. 1046:151-155.

33. Riaz, S., Tenscher, A. C., Ramming, D. W., and Walker, M. A. 2011. Using a limited mapping strategy to identify major QTLs for resistance to grapevine powdery mildew (Erysiphe necator) and their use in markerassisted breeding. Theor. Appl. Genet. 122:1059-1073.

34. Spanu, P. D., Abbott, J. C., Amselem, J., Burgis, T. A., Soanes, D. M., Stüber, K., Ver Loren van Themaat, E., Brown, J. K., Butcher, S. A., Gurr, S. J., Lebrun, M. H., Ridout, C. J., Schulze-Lefert, P., Talbot, N. J., Ahmadinejad, N., Ametz, C., Barton, G. R., Benjdia, M., Bidzinski, P., Bindschedler, L. V., Both, M., Brewer, M. T., Cadle-Davidson, L., Cadle-Davidson, M. M., Collemare, J., Cramer, R., Frenkel, O., Godfrey, D., Harriman, J., Hoede, C., King, B. C., Klages, S., Kleemann, J., Knoll, D., Koti, P. S., Kreplak, J., López-Ruiz, F. J., Lu, X., Maekawa, T., Mahanil, S., Micali, C., Milgroom, M. G., Montana, G., Noir, S., O'Connell, R. J., Oberhaensli, S., Parlange, F., Pedersen, C., Quesneville, H., Reinhardt, R., Rott, M., Sacristán, S., Schmidt, S. M., Schön, M., Skamnioti, P., Sommer, H., Stephens, A., Takahara, H., Thordal-Christensen, H., Vigouroux, M., Wessling, R., Wicker, T., and Panstruga, R. 2010. Genome expansion and gene loss in powdery mildew fungi reveal tradeoffs in extreme parasitism. Science 330:1543-1546.

35. Tabien, R. E., Li, Z., Paterson, A. H., Marchetti, M. A., Stansel, J. W., and Pinson, S. R. M. 2000. Mapping of four major rice blast resistance genes from 'Lemont' and 'Teqing' and evaluation of their combinatorial effect for field resistance. Theor. Appl. Genet. 101:1215-1225.

36. Tan, M. Y. A., Hutten, R. C. B., Visser, R. G. F., and van Eck, H. J. 2010. The effect of pyramiding Phytophthora infestans resistance genes $R_{(P i-m c d 1)}$ and $R_{(P i-b e r)}$ in potato. Theor. Appl. Genet. 121:117-125.

37. Vleeshouwers, V. G., Rietman, H., Krenek, P., Champouret, N., Young, C., Oh, S. K., Wang, M., Bouwmeester, K., Vosman, B., Visser, R. G., 
Jacobsen, E., Govers, F., Kamoun, S., and Van der Vossen, E. A. 2008. Effector genomics accelerates discovery and functional profiling of potato disease resistance and Phytophthora Infestans avirulence genes. PLoS One 3:e2875.

38. Zhang, W. J., Hanisch, S., Kwaaitaal, M., Pedersen, C., and Thordal-Christensen, H. 2013. A component of the Sec61 ER protein transporting pore is required for plant susceptibility to powdery mildew. Front. Plant Sci. 4:127.
39. Zhang, W. J., Pedersen, C., Kwaaitaal, M., Gregersen, P. L., Mørch, S. M., Hanisch, S., Kristensen, A., Fuglsang, A. T., Collinge, D. B., and ThordalChristensen, H. 2012. Interaction of barley powdery mildew effector candidate CSEP0055 with the defence protein PR17c. Mol. Plant Pathol. 13:1110-1119.

40. Zhou, Y., Cao, Y., Huang, Y., Xie, W., Xu, C., Li, X., and Wang, S. 2009. Multiple gene loci affecting genetic background-controlled disease resistance conferred by R gene Xa3/Xa26 in rice. Theor. Appl. Genet. 120:127-138. 